\title{
Botulinum Toxin A- A valuable adjunct in improving the esthetic outcomes of surgically treated cases of unilateral primary cleft lip
}

\author{
Shreyas Orvakonde ${ }^{1 *}$, Bidyalaxmi Mutum ${ }^{2}$ \\ ${ }^{1}$ Resident, ${ }^{2}$ Private Practitioner, ${ }^{1}$ Dept. of Dentistry (Oral and Maxillofacial Surgery), Chamarajanagar Institute of Medical Sciences, \\ Chamarajanagar, Karnataka, India \\ *Corresponding Author: Shreyas Orvakonde \\ Email: drshre890@gmail.com
}

\begin{abstract}
In the surgical correction of the cleft lip, the surgeon faces numerous challenges which make the task of obtaining appreciable esthetic results an arduous one. A multitude of problems can present to the surgeon after the surgical repair of cleft lip, such as hypertrophic scar, peaking and notching. In such a scenario Botulinum Toxin A can help achieve improved esthetic results. Botulinum toxin type A is a powerful neurotoxin which is produced by the anaerobic organism Clostridium Botulinum and when injected into a muscle causes interference with the neurotransmitter mechanism producing selective, transient paralysis of the muscle, which in turn reduces scar contracture.

Aims: To evaluate the esthetic outcome of Botulinum Toxin A injection in cleft lip surgeries and to evaluate the role of Botulinum toxin A in unilateral cleft lip scars.

Materials and Methods: 30 healthy unilateral cleft lip patients reporting for cleft procedure were taken up for the study.

6-8 units of Botulinum Toxin A was injected (after test dose) along pre-determined points. Both objective (Photographic evaluation) and subjective (Patient questionnaire method) evaluation was carried out after 1 year.

Results: Photographic evaluation revealed that majority of the patients had either excellent or good esthetic outcomes. Scar characteristics were evaluated and most patients were happy or very happy with the surgical results.
\end{abstract}

Keywords: Botulinum Toxin A, Esthetic evaluation, Primary cheiloplasty, Subjective evaluation, Unilateral cleft lip.

\section{Introduction}

In the surgical correction of cleft lip, obtaining consistently good esthetic outcomes remain a challenge. The ideal end results in cleft lip surgery are seamless function, minimal surgical scars and a proportional lip contour. Even with precise technique ideal results may not be achieved owing to various factors like individual tissue response, muscular activity, wound healing etc. ${ }^{1}$

Skin tension perpendicular to an incision increases the chances of unfavorable scarring due to distracting forces exerted on the healing wound ${ }^{2}$, in such a context Botulinum Toxin A could help enhance esthetic results. According to a study by Atef A Fouda, Botulinum toxin A induced paralysis of the musculature subjacent to the surgical wound and subsequently minimized the repetitive tensile forces on the skin wound edges, resulting in a decreased fibroblastic response and subsequent hypertrophic scar formation. ${ }^{1}$ Botulinum Toxin A aims to negate such repetitive tensile forces resulting in an improved scar outcome.

There has been a paucity of literature and clinical studies which have evaluated the effects of Botulinum toxin A in enhancing the surgical outcomes of cleft lip repair. Our study aims to evaluate the esthetic outcome of cleft lip repair augmented with the use of botulinum toxin A.

\section{Material and Methods}

30 Healthy Unilateral cleft lip and palate patients reporting for cleft procedure were taken up for the study. (Ethical clearance obtained from the Institutional review board of the institution.)

\section{Inclusion criteria}

1. Systemically healthy unilateral cleft lip (primary cheiloplasty) patients between the ages of 3 months to 6 months of age.

\section{Exclusion criteria}

1. Subjects with any immunosuppressive and endocrine disorders such as diabetes mellitus, thyroid disorders and who are under medication that interferes with wound healing including anticoagulants.

2. Subjects with incomplete cleft lip.

3. Patients allergic to Botulinum Toxin A.

Modified Millard technique was employed to surgically correct the cleft lip (Fig. 1). 6-8 units of Botulinum Toxin A was administered on the day of suture removal $\left(7^{\text {th }}\right.$ Postoperative day) into 6 predetermined points on either sides (Fig. 2) Photographic evaluation (objective evaluation) and subjective evaluation was carried out after 1 year.

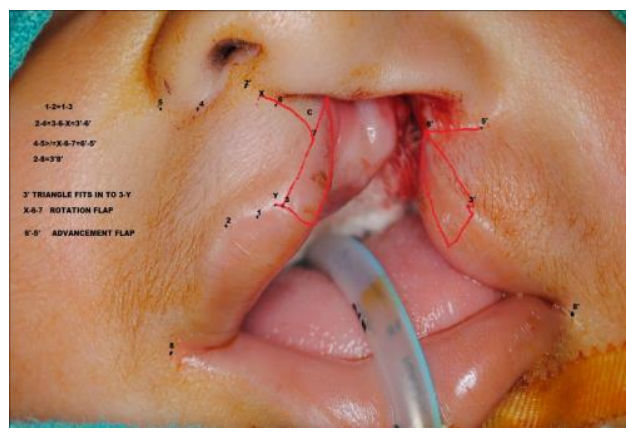

Fig. 1 


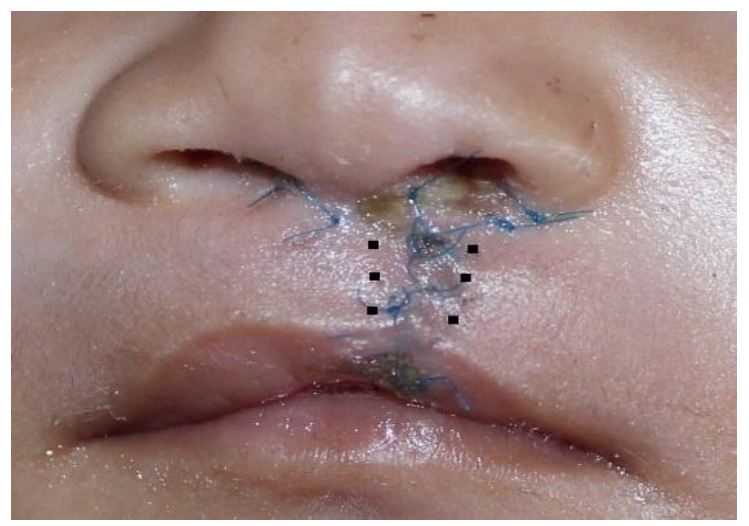

Fig. 2

\section{Evaluation of outcome}

Photographic evaluation done by two independent observers (senior professors at our unit) using a scale $\mathrm{e}^{3}$ obtained from a previous study which was modified to suit the present study. Photographic standardization was achieved by clicking patient photographs with the same DSLR (cannon EOS 1200D), in a standard mode and at a distance of 5 feet. Resolution of 800 X 600 px, was used for evaluation. The method used for rating facial appearance has been described by peerlings et al. Two views were used to judge the facial appearance i.e. Photograph showing the full face (Fig. 3) and a cropped version of the same photograph revealing only the nose and mouth. (Surrounding facial features obscured, with the only nose and lip being visible- Fig. 3,4$))^{4,5}$

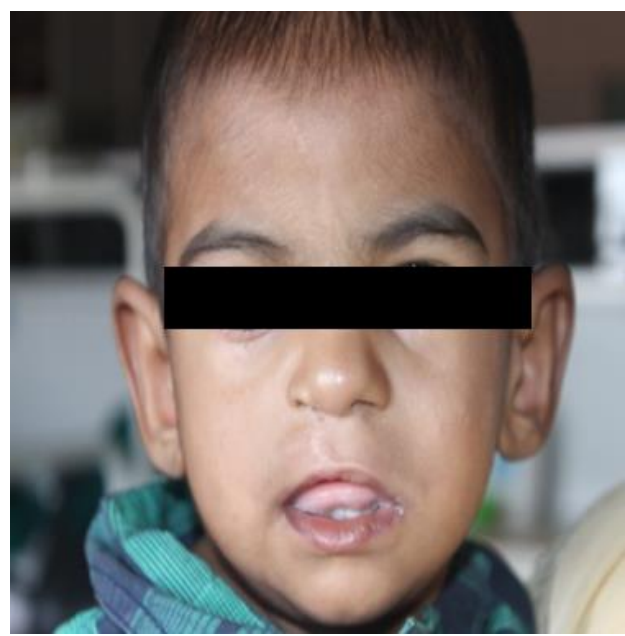

Fig. 3

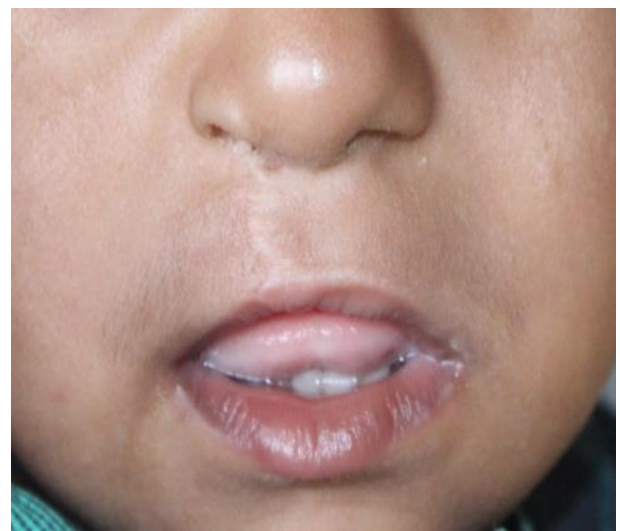

Fig. 4

Modified scale for photographic evaluation. ${ }^{3}$

\begin{tabular}{|c|c|c|c|c|c|c|}
\hline Parameter & \multicolumn{2}{|l|}{$\begin{array}{r}\text { Score 1 } \\
\end{array}$} & \multicolumn{2}{|l|}{ Score 2} & \multicolumn{2}{|l|}{ Score 3} \\
\hline White roll match & $\begin{array}{l}\text { No } \\
\text { disparity present }\end{array}$ & 1 & Disparity less than $2 \mathrm{~mm}$ & 2 & $>2 \mathrm{~mm}$ & 3 \\
\hline Vermillion match & No disparity & 1 & $\begin{array}{l}\text { Disparity of wet and dry } \\
\text { mucosa }<2 \mathrm{~mm}\end{array}$ & 2 & $>2 \mathrm{~mm}$ & 3 \\
\hline Sear appearance & No Hypertrophy & 1 & $\begin{array}{l}\text { Hypertrophy with no } \\
\text { disturbance of cupids bow or } \\
\text { columella }\end{array}$ & 2 & $\begin{array}{l}\text { Hypertrophy with } \\
\text { disturbance of cupids } \\
\text { bow or columella }\end{array}$ & 3 \\
\hline Cupids bow form & No disparity & 1 & $\begin{array}{l}\text { Distortion on cleft side } \\
<2 \mathrm{~mm}\end{array}$ & 2 & $>2 \mathrm{~mm}$ & 3 \\
\hline Lip length & $\begin{array}{l}\text { Equal length on } \\
\text { cleft and non-cleft } \\
\text { sides }\end{array}$ & 1 & $\begin{array}{l}\text { Shortening on cleft side } \\
>2 \mathrm{~mm}-5<\mathrm{mm}\end{array}$ & 2 & $\begin{array}{l}\text { Shortening on cleft } \\
\text { side }>5 \mathrm{~mm}\end{array}$ & 3 \\
\hline Total & \multicolumn{2}{|l|}{5} & \multicolumn{2}{|l|}{10} & \multicolumn{2}{|l|}{15} \\
\hline \multicolumn{2}{|l|}{$\begin{array}{l}\text { Excellent - } 5 \\
\text { Good - 6-10 } \\
\text { Poor - 11-15 }\end{array}$} & \multicolumn{3}{|c|}{$\begin{array}{l}1^{\text {st }} \text { Independent observer } \\
\text { Total score } \\
\text { Final grade- }\end{array}$} & \multicolumn{2}{|l|}{$\begin{array}{l}2^{\text {nd }} \text { Independent observer } \\
\text { Total score- } \\
\text { Final grade }\end{array}$} \\
\hline
\end{tabular}

Individual parameters such as white roll match, vermillion match, scar appearance, cupids bow form and lip length were assessed and scored. Individual scores were totalled and the final score was graded as excellent, good and poor. 


\section{Subjective evaluation}

Patient Questionnaire- Christofides A et al. ${ }^{6}$

\section{Patient questionnaire}

Please answer the following questions and tick the appropriate boxes below. The aim is to identify your satisfaction with your cleft lip repair. In particular we are assessing the scar and wish to ascertain exactly what bothers you the most. Since the average age of the patient population was less than 6 months the mother of the child being evaluated was asked to fill the below questionnaire.

\begin{tabular}{|l|l|}
\hline 1 & Very satisfied (Very Happy) \\
\hline 2 & Doesn't bother me much (Happy) \\
\hline 3 & Could have been better (Okay) \\
\hline 4 & Not satisfied at all (Unhappy) \\
\hline
\end{tabular}

1. Are you satisfied with the colour of the scar?

\begin{tabular}{|l|l|l|l|l|l|l|l|}
\hline 1 & & 2 & & 3 & & 4 & \\
\hline
\end{tabular}

2. Are you satisfied with the texture (smoothness) of the scar?

\begin{tabular}{|l|l|l|l|l|l|l|l|}
\hline 1 & & 2 & & 3 & & 4 & \\
\hline
\end{tabular}

3. Are you satisfied with the width of the scar?

\begin{tabular}{|l|l|l|l|l|l|l|l|}
\hline 1 & & 2 & & 3 & & 4 & \\
\hline
\end{tabular}

4. Are you satisfied with the thickness (amount of budging above the skin) of the scar?

\begin{tabular}{|l|l|l|l|l|l|l|l|}
\hline 1 & & 2 & & 3 & & 4 & \\
\hline
\end{tabular}

5. What part of the scar bothers you the most?

\begin{tabular}{|l|l|}
\hline Upper part closer nose & \\
\hline Middle part & \\
\hline Lower part closer to lip & \\
\hline
\end{tabular}

Descriptive statistics was used to analyse the data.

\section{Results}

\section{Photographic evaluation}

This was carried out by two independent observers on the basis of a scale obtained, which was later modified to suit the current study. Two independent observers evaluated white roll match, vermillion match, scar appearance, cupids bow form and lip length and subsequently scored each of these parameters. These individual scores for each parameter were totalled and the final grading allotted.

\section{1st Independent observer}

After evaluation, 9(20.00\%) patients were deemed to have EXCELLENT esthetic outcome, 17 (56.66\%) patients had a GOOD outcome and the results of the remaining 2(13.3\%) patients was POOR.

\section{$2^{\text {nd }}$ Independent Observer}

The surgical results of $11(36.66 \%)$ patients were EXCELLENT and $19(63.33 \%)$ patients were adjudged to have a GOOD esthetic outcome.

Table 1: Photographic evaluation

\begin{tabular}{|c|c|c|c|}
\hline $1^{\text {st }}$ Independent Observer & Excellent & 9 & $30.00 \%$ \\
\hline & Good & 17 & $56.66 \%$ \\
\hline $2^{\text {nd }}$ Independent Observer & Poor & 4 & $13.33 \%$ \\
\hline & Excellent & 11 & $36.66 \%$ \\
\hline
\end{tabular}

\section{Subjective evaluation}

Colour, texture width and thickness of the scar was evaluated. Most patients were either very happy or happy with scar characteristics evaluated (Table 2).

Table 2: Subjective evaluation

\begin{tabular}{|l|l|c|c|c|c|}
\hline & & Color & Texture & Width & Thickness \\
\hline Subjective evaluation & Very happy & $15(50 \%)$ & $19(63.3 \%)$ & $20(66.6 \%)$ & $17(56.6 \%)$ \\
\hline & Happy & $9(30 \%)$ & $8(26.6 \%)$ & $6(20 \%)$ & $10(33.3 \%)$ \\
\hline & Okay & $3(10 \%)$ & $2(6.6 \%)$ & $2(6.6 \%)$ & $1(3.3 \%)$ \\
\hline & Unhappy & $3(10 \%)$ & $1(3.3 \%)$ & $2(6.6 \%)$ & $2(6.6 \%)$ \\
\hline
\end{tabular}
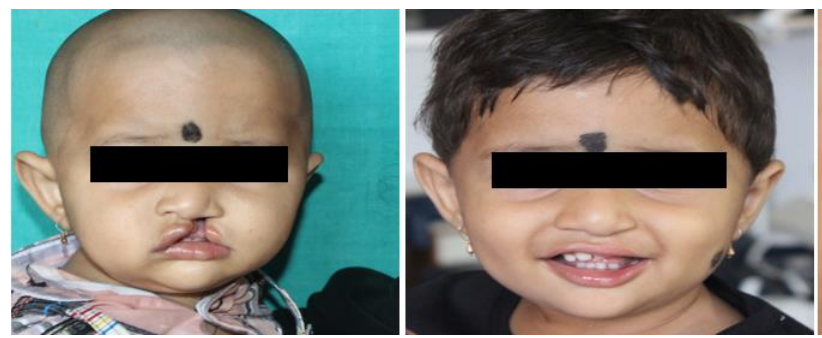

Fig. 5: Pre op and post op Photographs. Note the well formed lip architecture with good scar characteristics 


\section{Part of the scar which created maximum concern}

The lower part of the scar created most concern in 26 patients, whereas the upper area of the scar bothered 4 patients.

\section{Discussion}

Photographic evaluation carried out by two independent observers evaluated esthetic parameters such as white roll match, vermillion match, scar appearance, cupids bow form and lip length. Majority of the outcomes were rated as excellent or good (Table 1). The results obtained is similar to the studies of Chun-Shin-Chang. ${ }^{7}$

The central theme of the subjective evaluation was scar evaluation. Most of the parents were either very happy or happy with the colour, width, texture and thickness of the scar. The lower part of the scar created most concern (26 patients). This can be attributed to the innate deficiency of muscle present on the cleft side. Also this area corresponds to the area of peaking and notching. More no of units into this specific area could have negated this issue and this remains an area of further study.

The goal of primary cleft lip repair is to constitute oral competence and a functional muscular sphincter. Of equal importance is the cosmetic reconstruction of the lip. The effort is towards correct alignment of Cupid's bow, harmonious vermilion, and precise reconstruction of the philtral column. ${ }^{8}$ Optimum outcomes are often elusive due to post-surgical scar contracture which results in poor esthetic appearance of the lip. Despite precise surgical techniques, scar contracture can appear in few patients owing to the inherent nature of wound healing. The muscles of facial expression lie superficially and do not have bony attachments. They create expressions by altering the tension of the adjacent skin. However skin tension that is perpendicular to an incision is known to increase the risk of unfavorable scarring as a result of distracting forces exerted on the healing wound. ${ }^{9}$ in such a scenario Botulinum Toxin A could help achieve improved esthetic results. There is enough clinical indicators that Botulinum toxin A can improve scar characteristics and inhibit its growth by creating temporary chemoimmobilisation which in turn does not lead to distracting forces on the healing tissues thus enabling a conducive atmosphere devoid of increased fibroblastic activity. The end result of this chemoimmobilisation is a well formed imperctible scar.

Cleft craft has evolved over the years and has employed various adjuncts such as NAM, lip taping, formulations to decrease scarring, use of silicon gels/sheets to enhance surgical results. ${ }^{10,11}$ Botulinum Toxin A is a step in such a direction and our study demonstrated improved scar characteristics as evaluated both objectively and subjectively. Use of botulinum toxin A could decrease the need for future revisions and surgical interventions thereby justifying the cost involved.

\section{Conclusion}

A scar is a dermal fibrous replacement tissue resulting from a wound that has healed by resolution. The skin present on the upper lip is at risk of hypertrophic scars due to the presence of constant movements of the underlying orbicularis oris muscle during routine activities such as speech, eating, drinking and facial expressions. Thus there is the transmission of tensile forces on the healing scar. Botulinum toxin A plays a vital role in negating such an effect.

The current study investigated Botulinim Toxin A chemoimmobilisation and its effect on post-operative esthetic results. The results of our study clearly indicate the value Botulinium Toxin A in terms of obtaining consistently good esthetic outcomes.

\section{Source of Funding}

None.

\section{Conflict of Interest}

None.

\section{References}

1. Fouda AA. Effects of orbicularis-oris muscle injection with botox on cleft lip revision surgery scar. Am J Res Commun. 2013;1(3):115-22.

2. Chang CS, Wallace CG, Chen PK. Botulinum toxin to improve results in cleft lip repair; a double -blinded, randomised, vehicle controlled clinical trial. Plast Reconstr Surg. 2014;134(3):511-6.

3. Reddy SG. Comparison of three incisions to repair complete unilateral cleft lip. Plast Reconstr Surg. 2010;125(4):1208-16.

4. Bongaarts CA, Prahl-Andersen B, Bronkhorst EM, Spauwen PH, Mulder JW, Vaandrager JM, Kuijpers-Jagtman AM. Effect of infant orthopedics on facial appearance of toddlers with complete unilateral cleft lip and palate. Cleft Palate Craniofac J. 2008;45(4):407-13.

5. Asher-McDade C, Roberts C, Shaw WC, Gallager C. Development of a method for rating nasolabial appearance in patients with clefts of the lip and palate. Cleft Palate Craniofac J. 1991;28(4):385-90.

6. Christofides E, Potgieter A, Chait L. A long term subjective and objective assessment of the scar in unilateral cleft lip repairs using the Millard technique without revisional surgery. J Plast Reconstr Aesthet Surg. 2006;59(4):380-6.

7. Chang CS, Wallace CG, Hsiao YC, Chang CJ, Chen PK. Botulinum Toxin to improve results in cleft lip repair; A double -blinded, Randomised, vehicle controlled clinical trial. PLoS One. 2014; 9(12):e115690.

8. Tibesar RJ, Black A, Sidman JD. Surgical repair of cleft lip and cleft palate. Oper Tech Otolaryngol. 2009;20:245-55.

9. Doonquah L, Ogle OE. Scar revision of the cleft lip. Oral Maxillofac Surg Clin North Am. 2002;14(4):425-37.

10. Puri N, Talwar A. The efficacy of Silicone Gel for the treatment of Hypertrophic Scars and keloids. J Cutan Aesthet Surg. 2009;2(2):104-6.

11. McCarthy M. An evaluation of evidence regarding application of silicon gel sheeting for the management of hypertrophic scars and keloids. J Clin Aesthet Dermatol. 2010;3(11):39-43.

How to cite this article: Orvakonde $\mathrm{S}$, Mutum $\mathrm{B}$. Botulinum- A valuable adjunct in improving the esthetic outcomes of surgically treated Toxin A cases of unilateral primary cleft lip. Int J Oral Health Dent 2020;6(1):18-21. 